\title{
Estrategias frente al intrusismo en gineco obstetricia
}

\section{Strategies against intrusiveness in obstetrics and gynecology}

Correspondencia David Estela-Ayamamani david.estela.a@gmail.com

Recibido: 19/12/2016 Aprobado: 21/12/2016

Citar como: Estela-Ayamamani $D$, De Vinatea-Serrano $L$, Benavides-Morales D. Estrategias frente al intrusismo en gineco obstetricia. Acta Med Peru. 2016;33(4):332-3

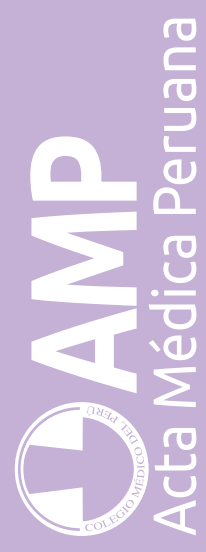

\author{
David Estela-Ayamamani ${ }^{1}{ }^{2}$, Luis De Vinatea-Serrano ${ }^{1}$, Dante Benavides- \\ Morales ${ }^{1,2}$ \\ 1 Escuela de Medicina, Universidad Peruana de Ciencias Aplicadas. Lima, Perú. \\ 2 Departamento de Obstetricia y Ginecología. Hospital Nacional Edgardo Rebagliati Martins. Lima, Perú.
}

\section{Sr. Editor:}

El intrusismo en medicina es el ejercicio de la profesión por personas que no tienen los requisitos para ejercer legalmente como médicos ${ }^{[1]}$. Es decir, cuando se realizan actos que corresponden a una profesión sin tener el grado académico que le brinda las habilidades para realizarlos. En el Perú, en los últimos meses se han hecho públicos diversos casos de obstetras que ejercen funciones usualmente realizadas por los ginecoobstetras ${ }^{[2]}$.

El artículo 363 del Código Penal sanciona con pena privativa de la libertad el ejercicio de la profesión médica sin cumplir los requisitos legales. Sin embargo, no existe una norma que delimite el área de actuación ni las competencias que debe adquirir cada profesional. Este vacío legal genera que cada profesional brinde atención en ginecología y obstetricia de acuerdo a lo que considere conveniente. Todo esto se ve reforzado por el desconocimiento de la población acerca del perfil de estas profesiones.

En los últimos meses, se han incrementado las oportunidades de capacitación para las obstetras, mediante cursos, congresos y diplomados avalados por universidades; muchos de ellos instruyendo en actividades que actualmente la realizan exclusivamente los ginecoobstetras ${ }^{[2]}$. Mediante el Decreto Supremo No 026-2016-SA publicado en el Diario El Peruano, se aprobó el reglamento de residentado en obstetricia, el cual tiene como finalidad regular los estudios de segunda especialidad de estos profesionales ${ }^{[3]}$.

Es conocido que la densidad de recursos humanos y el logro de indicadores en salud mantienen una relación directa ${ }^{[4]}$. Por ello, el Perú necesita una sólida base de profesionales para solucionar los problemas en salud, evitando la mala praxis y, particularmente, la impericia. Es necesario que estos profesionales trabajen en equipo en todos los niveles de atención, lo cual incluye entre sus pilares la interdependencia, la interdisciplinariedad y la interacción comunicativa ${ }^{[4,5]}$.

Actualmente, el intrusismo en ginecoobstetricia es un problema de salud pública. Se han formulado estrategias administrativas a través del Comité de Lucha contra el Intrusismo Profesional del Colegio Médico del Perú, cuya función es la investigación y la denuncia del intrusismo ${ }^{[2]}$. Sin embargo, no se han logrado soluciones claras al problema.

Consideramos que la base de medidas a tomar frente al intrusismo debe consistir en la creación de un Manual de Organización y Funciones para cada profesional, aclarando las facultades que tienen en el ejercicio de su labor. Asimismo, se debe replantear y cumplir las normas que contemplen sanciones por 
intrusismo profesional. Además, proponemos que se uniformice las mallas curriculares de las facultades de obstetricia del país para que los egresados tengan competencias similares; y que se eduque a la población acerca de las diferencias entre estas dos áreas de la salud.

Consideramos también que todo profesional de salud tiene derecho a la capacitación, más aún, si contribuye a la mejora sanitaria del país. No obstante, esta debe estar dirigida al perfil de cada profesional, contando con el respaldo de las autoridades universitarias que actualmente brindan capacitación irregular a los obstetras. Finalmente, sugerimos promover el trabajo interdisciplinario en los establecimientos de salud y promover un mejor clima laboral en cada institución, considerando como fin último el bienestar de los pacientes.

\section{REFERENCIAS BIBLIOGRÁFICAS}

1. Machado $\mathrm{Cl}$. Adecuación típica del ejercicio ilegal de la actividad médica en España y Colombia. Derecho penal y criminología. 2009;30(88):69-92.

2. Colegio Médico del Perú. Comité Asesor Transitorio de Lucha Contra el Intrusismo Profesional [Internet]. Lima: CMP; 2016 [citado el 19 de diciembre de 2016]. Disponible en: http://cmp. org.pe/contraintrusismo

3. Reglamento del Residentado en Obstetricia, Decreto Supremo. No. 026-2016-SA. (Jul. 23, 2016)

4. Instituto de Desarrollo de Recursos Humanos, Observatorio Nacional de Recursos Humanos en Salud. El Perú respondiendo a los desafíos de la década de los recursos humanos en salud. Lima: Ministerio de Salud; 2006.

5. Organización Panamericana de la Salud. Sistemas de salud basados en la Atención Primaria de Salud: Estrategias para el desarrollo de los equipos de laAtención Primaria de Salud. Washington, D.C.:OPS; 2008.

\section{Las ediciones anteriores de Acta Médica Peruana están disponibles en:}

\section{www.redalyc.org}

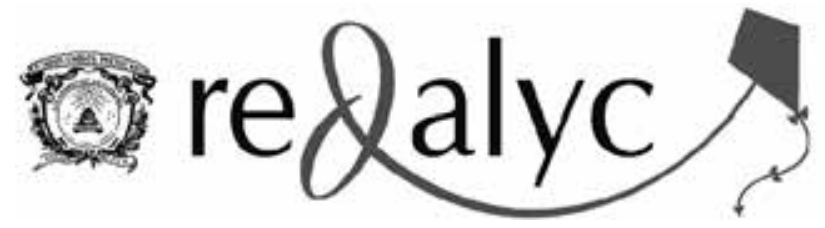

